Música, teatro y cine: medios y funciones

\title{
La vertiente psicofísica/intercultural, su idoneidad para formar intérpretes capaces de asumir la escena contemporánea
}

\author{
Roberto Bautista Díaz \\ Universidad de Costa Rica, Costa Rica \\ rkteatro@gmail.com \\ https://orcid.org/0000-0002-5881-9700
}

Recibido: 30 de setiembre de 2019

Aceptado: 26 de octubre de 2019

Resumen: Los caminos de la formación actoral han confluido históricamente en la necesidad de organicidad y verosimilitud de la interpretación para enfrentar la escena. Actualmente, con la diversidad poética que plantea la escena contemporánea es necesario revisar las búsquedas de la formación para comprender las oportunidades que cada vertiente formativa aportó a la visión del hecho escénico desde la interpretación. El marco en el que esta reflexión cobra sentido es en los intersticios entre la pedagogía, el arte teatral y la interculturalidad. Nos planteamos un breve análisis histórico sobre la formación actoral, en este sentido, para pensar la posibilidad de preguntarnos sobre la vertiente psicofísica intercultural como una oportunidad decolonial sobre la formación actoral.

Palabras clave: Teatro, interpretación, vertientes formativas, psicofísico, intercultural.

The psychophysical/ intercultural trend, its suitability to train interpreters capable of assuming the contemporary scene.

\section{(c) (i) (9) (2)}

La Revista Estudios es editada por la Universidad de Costa Rica y se distribuye bajo una Licencia Creative Commons Atribución-NoComercial-CompartirIgual 3.0 Costa Rica. Para más información envíe un mensaje a 
Abstract: The paths of acting education have historically converged in the need for organicity and credibility of interpretation to face the scene. Currently, with the poetic diversity proposed by the contemporary scene, it is necessary to review the training searches to understand the opportunities that each formative aspect contributed to the vision of the stage from the acting angle. The framework in which this reflection makes sense is in the interstices between pedagogy, theatre and interculturality. We consider a brief historical analysis of acting instruction, in this sense, to think about the possibility of asking ourselves about the intercultural psychophysical trend as a decolonial opportunity for acting education.

Keywords: Theater, interpretation, formative trends, psychophysical, interculturality.

\section{Introducción}

\section{Introducción}

La escena teatral contemporánea habla desde una pluralidad de lenguajes cada vez más creciente. Como bien afirma Zarrilli (2009), "[...] se espera que los actores contemporáneos se presenten en un amplio espectro de dramaturgias nuevas, alternativas y "post dramáticas", tales como las obras de teatro de letras, guiones abiertos o "teatro físico" (p.7). Pensar en la formación de intérpretes para una escena de semejante diversidad, nos exige revisar las diferentes pedagogías que han colaborado en el crecimiento profesional y artístico de actores y actrices. ¿Cómo brindar las herramientas necesarias para generar procesos formativos sólidos, que se integren a espacios y estéticas de representación tan diversas como las que enfrentamos en la actualidad? ¿A cuál camino formativo debemos apelar para generar un aprendizaje desde la integralidad del cuerpo y la mente, que su vez, colabore con la formación de intérpretes más conscientes de su propiocepción y de sus herramientas expresivas?

\section{(c) (i) (2)}

La Revista Estudios es editada por la Universidad de Costa Rica y se distribuye bajo una Licencia Creative Commons Atribución-NoComercial-CompartirIgual 3.0 Costa Rica. Para más información envíe un mensaje a 
Bajo estas premisas nos proponemos identificar la pertenencia de la vertiente psicofísica/intercultural en los procesos formativos y de entrenamiento actoral. Cabe señalar que desde nuestro punto de vista, lo intercultural coloca las búsquedas de otras culturas en una horizontalidad que rompe con la tradición occidental, generando la posibilidad reconocer de igual manera, las prácticas culturales de la periferia o aquellas que no fueron inscritas dentro de un concepto de "evolución" de la escena, impuesto por el pensamiento euro centrista. Entendemos lo intercultural por esa simbiosis que se establece entre culturas diferentes, donde se propicia un intercambio bilateral en el que se asumen las diferencias como una oportunidad de enriquecimiento recíproco.

Partiendo de un pensamiento interdisciplinario que convoca al teatro, la pedagogía y la interculturalidad, nos enfocaremos en aquellos aspectos que a lo largo de los diferentes períodos han ido alimentando la formación actoral. A través de un breve recorrido histórico desde la visión europea, a falta de una mirada descolonizada de la historia teatral, nos detendremos en aquellos caminos formativos que otorgan mayor protagonismo al entrenamiento actoral como vehículo de preparación y aprendizaje de la técnica interpretativa. Revelaremos patrones sobresalientes en cada propuesta que las hace distintivas y a la vez, posibilitan caracterizar los planteamientos formativos y estéticos de las diferentes escuelas o maestros.

\section{Propuestas que rigen al análisis}

Estructuraremos nuestro análisis apoyados en dos teóricos, Ruíz (2012), que enfoca su trabajo en un recorrido histórico de las escuelas de actuación del siglo XX; y Rojas (2012) quien estudia las metodologías pedagógicas de las diferentes escuelas también del siglo XX.

Ruiz (2012) por su parte, organiza un recorrido teórico y práctico a partir de las particularidades que logra identificar en los diferentes acercamientos a la

\section{(c) (i) (9) (2)}

La Revista Estudios es editada por la Universidad de Costa Rica y se distribuye bajo una Licencia Creative Commons Atribución-NoComercial-CompartirIgual 3.0 Costa Rica. Para más información envíe un mensaje a 
formación actoral y la práctica escénica. De esta manera, consigue establecer diferentes relaciones entre creadores y técnicas interpretativas como: relaciones directas, maestro-alumno, objetiva y relaciones indirectas, en aspectos éticos y/o técnicos, subjetiva. Con base en dichas relaciones, define dos grupos de diferentes tendencias: racionalista e irracionalista.

A partir de esta concepción Rojas (2012) plantea una re organización de las tendencias propuestas por Ruiz en tres grandes grupos a los que definirá como Vertientes Formativas (p.65). Los criterios en los que se basa la autora para plantear esta re organización, parecieran responder al enfoque con el que cada maestro y discípulo de los convocados por Ruiz, aborda el trabajo físico, corporal y psicológico en el proceso formativo. Los grupos o vertientes que a continuación mostramos no incluyen la totalidad de los exponentes que compila Rojas, pero permite tener una idea más precisa de su conformación.

- La vertiente Stanislavskiana/Psicológica es encabezada por Konstantín Stanislavski (1863-1938), y continuada por Lee Strasberg (1901-1982), Stella Adler (1901-1992), Sanford Meisner (1905-1997)

- Vertiente Gestual, compila el trabajo de creadores como Francois Delsarte (1811-1871), Jacques Copeau (1879-1949), Rudolph von Laban (18791958), Étienne Decroux (1898-1991) y Jacques Lecoq (1921-1999).

- Vertiente Psicofísica/intercultural, donde agrupa a Vsévolod Meyerhold (1874-1940), Michael Chéjov (1891-1955), Jerzy Grotowski (1933-1999), Antonin Artaud (1896-1948), Eugenio Barba (1936) entre otros.

Uno de los valores que rescatamos de la re organización que plantea Rojas es que establece criterios para cada grupo, además de su porosidad y permeabilidad, que permiten la integración de nuevos exponentes o seguidores a las diferentes 
Revista Estudios, (39), 2019.

Diciembre 2019-Mayo 2020

ISSN 1659-3316

Bautista Díaz Roberto

variantes formativas ${ }^{1}$. Si quisiéramos asumir esta segmentación de las búsquedas con un carácter evolutivo, podríamos afirmar que las experiencias generadas en el grupo de la variante formativa Psicofísica/Intercultural, desde nuestra visión, tienden a asumir el compromiso interpretativo con un carácter holístico e integrador, en ocasiones más evidente que en las anteriores. He acá que encontramos en la interculturalidad un factor crucial para el camino de la pedagogía actoral en este nuestro universo diverso y globalizado.

Nuestro objetivo se enfoca en evidenciar el compromiso que se adquiere con el entrenamiento y la potenciación de la expresividad del cuerpo de las y los interpretes en la vertiente Psicofísica/Intercultural. La cual brinda el arsenal necesario para afrontar los procesos formativos de los actores y actrices en nuestros espacios de formación actoral. Paralelo a esto, reafirmamos una empatía con las búsquedas que se trazan dentro de esta variante formativa, pues el procurar la comunión del cuerpo y la mente del actor, no persigue otra cosa que dotar a las y los intérpretes en formación, de herramientas fundamentales para asumir la variedad interpretativa que demanda la escena teatral a la que nos enfrentamos, a la vez que abre un camino para establecer acercamientos formativos con carácter decolonial.

\section{Recorrido histórico por algunas prácticas del ejercicio actoral}

El arte de la interpretación en Occidente aparece y permanece como una actividad empírica por mucho tiempo. Si bien es cierto, dicha actividad llamó la atención de pensadores como Platón y Aristóteles, tuvimos que esperar varios siglos para que otros teóricos prestaran atención al fenómeno artístico y social que es el teatro.

\footnotetext{
1 Se sabe que la vertiente Psicofísica/Intercultural bebe de la vertiente Gestual y viceversa, y que en la práctica de la enseñanza, no existe tal separación. Incluso, se puede afirmar que lo mismo ocurre entre las tres vertientes que propongo, pues naturalmente, dependiendo del planteamiento metodológico del profesor de interpretación, las técnicas de una u otra vertiente se pueden mezclar y combinar entre sí. (Rojas, 2012, p.67).
}

\section{(c) (i) (2) (2)}

La Revista Estudios es editada por la Universidad de Costa Rica y se distribuye bajo una Licencia Creative Commons Atribución-NoComercial-Compartirlgual 3.0 Costa Rica. Para más información envíe un mensaje a revistaestudios.eeg@ucr.ac.cr. 
En los orígenes de este arte, se puede apreciar como la técnica actoral se reducía a la declamación. Los primeros actores, en la Grecia del siglo V y IV, estaban avocados a perfeccionar los recursos de la declamación, la potencia de la voz y una gestualidad algo extrovertida o extra cotidiana, que respondía a determinadas convenciones de la propia escena. Según Meyer-Dinkgräfe:

Parece que el estilo de actuación en la antigua Grecia era bastante poco realista [...] Los gestos tenían que ser amplios para ser inteligibles, y de hecho encontramos que se emplearon gestos simples para expresar emociones fundamentales: para expresar pena, el actor pudo haberse tapado la cabeza con su capa, o simplemente mirar hacia abajo. (2001, p.10). (Traducción propia).

Por otra parte en Roma, se comenzaron a generar algunas diferencias en la forma de abordar la creación teatral tanto en lo referente al oficio escénico mismo, como a nivel arquitectónico. Sin embargo, en lo que se refiere a la técnica actoral, no se registraron mayores cambios.

Los interpretes romanos se constituían en estructuras que comenzaron a complejizarse: "El empresario (conductor) pagaba entonces tanto al autor, que le cedía (definitivamente o temporalmente) el derecho de representación, como al director de los actores (dóminus gregis), el cual es de suponer que a su vez pagase a los otros actores" (D’Amico, 1972, p.99). A pesar de toda la información que puede ser consultada sobre este período de la historia teatral en occidente, no podríamos aseverar que exista, hasta el momento, algún documento que recoja formas de preparación física, específica y exclusiva; más allá de lo citado por los autores y estudiosos del teatro greco-latino.

Gracias a las observaciones de Quintiliano (35-95dc), sabemos que la interpretación, al menos durante la primera centuria, exigía de sus participantes 
Revista Estudios, (39), 2019.

Diciembre 2019-Mayo 2020

ISSN 1659-3316

Bautista Díaz Roberto

poner todo el cuerpo en función de los discursos, para de esta forma llegar a los espectadores con mayor efectividad.

Y los actores, con especialidad los latinos, acostumbran representar de una manera que hacen con toda propiedad el papel que desempeñan. Mas en el mismo semblante sirven de muchísimo los ojos, por los cuales más que por ninguna otra cosa se muestra el alma de manera que aun sin moverse, no solo se reviste de claridad con la alegría, sino que con la tristeza se cubren como de una nube. Además de esto, la naturaleza les dio las lágrimas por intérpretes del alma, las cuales o nacen del sentimiento o provienen de la alegría. Con el movimiento muestran conato en una cosa o en indiferencia, soberbia, fiereza, dulzura o aspereza, de todas las cuales formas se revestirá el orador según el lance lo pidiere. (Quintiliano, s.f, p.284).

Podemos asumir entonces que existía por parte de los actores de la época, una intención de recurrir a alguna clase de recurso técnico que colaborara en la potenciación o en cargar de interés y veracidad sus discursos. Quintiliano nos hace transitar de manera detallada por los músculos y por algunas partes del rostro, que nos hace suponer que los actores romanos en el siglo I d. C manejaban con cierta conciencia. Esto les permitía hacer más plausibles sus intervenciones, a la vez que hacían visibles los procesos de interiorización por los que atravesaban o eran atravesados durante la interpretación de sus personajes.

Al comienzo de la Edad Media en Europa ${ }^{2}$, las formas de teatro anteriores tienden a desaparecer. En paralelo ocurre una diversificación o una "versatilización" de la

2 La Edad Media europea ha sido asumida, en muchas ocasiones, como un período de poca diversidad creativa en la escena teatral de aquella époc, sin embargo autores como MeyerDinkgräfe logran identificar aportes sustanciales a la actividad teatral:

Después de que el Imperio Romano se desintegró, el teatro entró en un largo período de casi inexistencia durante la Edad Media temprana (900-1050). Brockett, sin embargo, identifica tres remanentes. Primero, había grupos de mimos itinerantes, que incluían todo

\section{(c) (i) (2)}

La Revista Estudios es editada por la Universidad de Costa Rica y se distribuye bajo una Licencia Creative Commons Atribución-NoComercial-Compartirlgual 3.0 Costa Rica. Para más información envíe un mensaje a revistaestudios.eeg@ucr.ac.cr. 
Revista Estudios, (39), 2019.

Diciembre 2019-Mayo 2020

ISSN 1659-3316

Bautista Díaz Roberto

figura del actor la cual se fusiona con el juglar, el saltimbanqui, el malabarista, el titiritero, el acróbata, cómicos, cantores, etc. Cuando la acción escénica se traslada a la plaza pública, este nuevo espacio demanda de los actores un dominio técnico preciso y depurado de su arte. Se hacía indispensable por aquel entonces manejar suficientes herramientas histriónicas y/o lúdicas, para conseguir la atención de los transeúntes y la posterior remuneración por parte de estos.

Surge también durante este período, una forma de teatro con un marcado enfoque y finalidad religiosa. Los actores de estas obras, lejos de ser practicantes "profesionales", eran feligreses a los que se les exigía apegarse a los cánones de representación existentes, los cuales debían ser respetados para conservar el mensaje religioso dentro de la estructura litúrgica.

La búsqueda de esta fidelidad interpretativa a través de diferentes cánones es evidenciada por D’Amico (1972) quien se refiere a uno de ellos en particular: "[...] todavía existe el canon de un Concilio de Constantinopla que, desde el siglo VII, da prescripciones sobre la manera de representar la figura de Jesús en la Pasión. [...] En el siglo VIII Carlomagno, para obedecer al papa Adriano, ordenó que fuese adoptada en todas las iglesias del imperio, la liturgia romana" (p.134-135). Dicha "recomendación" fue acompañada por la decisión de enviar a cantores romanos a

tipo de "intérpretes". En segundo lugar, hubo juglares teutónicos, que cantaron y contaron historias de sus héroes tradicionales y así conservaron la historia. En tercer lugar, el teatro sobrevivió en los festivales locales, que atraía a artistas ambulantes.[...] A finales de la Edad Media (1300-1500) se desarrolló un drama religioso vernáculo. [...] Largos ciclos de juegos basados en el nacimiento, la vida, la muerte y la resurrección de Cristo se dividieron entre varios gremios, de modo que cada uno solo necesitaba unos pocos actores. Esos actores se mantuvieron como aficionados, aunque las demandas de los juegos podrían llegar a ser considerables: podrían tener que duplicar partes (evidencia, por ejemplo, de un evento en el que 300 actores interpretaron 494 papeles), y se esperaba que aprendieran sus líneas de memoria. (Hay evidencia de una mujer que memoriza 2300 líneas como Santa Catalina en 1468). Actuar en la Edad Media, argumenta Elliot, fue considerado como un arte que requiere tanto talento como formación; Su objetivo principal era mover las emociones de un público. (Meyer-Dinkgräfe, p. 13-14). (traducción propia).

\section{(C) $(\triangle \circ)$}

La Revista Estudios es editada por la Universidad de Costa Rica y se distribuye bajo una Licencia Creative Commons Atribución-NoComercial-CompartirIgual 3.0 Costa Rica. Para más información envíe un mensaje a revistaestudios.eeg@ucr.ac.cr. 
las diferentes iglesias para que los sacerdotes de otras regiones aprendieran los ritos litúrgicos de la manera correcta. Durante el desarrollo del drama religioso vernacular, los intérpretes de los personajes negativos tenían más libertad para elaborar sus propuestas actorales, sin embargo en su gran mayoría, no contaban con ninguna preparación específica para este fin.

Durante los dos siglos anteriores al renacimiento europeo, en Gran Bretaña, se realizaban encuentros teatrales de interpretación. Dichos encuentros fueron condicionando de alguna manera la profesionalización de los actores. Con el afán de participar en estos encuentros, los actores debían presentarse a audiciones luego de las cuales serían seleccionados para sus roles específicos.

Actuar en la Edad Media, argumenta Elliott, era considerado como un arte que requería tanto talento como formación; su objetivo principal era mover las emociones de una audiencia. Los actores eran elegidos por audición y una variedad de otros mecanismos de selección formalizados. Una fuente afirma que los criterios de selección fueron la astucia, la voz y la persona, lo que Tydeman equipara con la capacidad de actuación, el rango vocal y entrega y la presencia física. Se les daba dos semanas para aceptar el papel, después tenían que jurar y comprometerse, en algunos casos frente a un notario, a asistir a los ensayos y actuaciones con diligencia según las instrucciones, o enfrentar una serie de multas por romper el contrato. (Meyer-Dinkgräfe, 2001, p.14). (traducción propia)

Según lo visto hasta acá, pareciera que la legalización y formalización de los vínculos que comenzaron a establecerse entre empresarios y compañías, fueron de gran aporte a la consolidación de una profesionalización de la interpretación. La competencia y la exigencia en estas audiciones, demandaba de los participantes mayor preparación y dominio de alguna "técnica interpretativa".

\section{(c) (i) (2)}

La Revista Estudios es editada por la Universidad de Costa Rica y se distribuye bajo una Licencia Creative Commons Atribución-NoComercial-CompartirIgual 3.0 Costa Rica. Para más información envíe un mensaje a 
Revista Estudios, (39), 2019.

Diciembre 2019-Mayo 2020

ISSN 1659-3316

Bautista Díaz Roberto

Desde la grandilocuencia de la escena griega hasta los cánones de interpretación exigido por la iglesia fueron fraguando una "forma" de interpretación que no encontrará una verdadera ruptura hasta el renacimiento italiano.

Con la consolidación de la Commedia dell' Arte, la profesionalización y el entrenamiento actoral comenzaron a verse como algo indisoluble. A lo largo de este período la figura del actor alcanza el nivel de mayor complejidad hasta el momento.

En este teatro de actor ( $\mathrm{y}$ de actriz, lo cual era una novedad para la época), el énfasis se ponía en la destreza corporal, en el arte de remplazar largos discursos por algunos signos gestuales y de organizar la representación "coreográficamente", es decir, en función del grupo, y utilizando el espacio con vistas a una puesta en escena anticipada. El arte del intérprete consistía más en un arte de variación y coyuntura verbal y gestual que en una invención total y en una nueva expresión. (Pavis, 1980, p.82).

A finales del siglo XVIII, durante La llustración, aparece un texto que plantea una mirada introspectiva y crítica del arte de la interpretación. "La paradoja del Comediante" genera un gran revuelo ${ }^{3}$ por los cuestionamientos que su autor plantea sobre la verdadera esencia del arte de la actuación. Denis Diderot (17131784 ) en su trabajo, apunta aquellos compromisos que establece el "buen actor" con su público y cómo depurar la técnica interpretativa del comediante. El texto

\footnotetext{
3 La paradoja del comediante se convirtió en la fuente de una larguísima lucha entre los "emocionalistas", aquellos que abogaban por un actor lleno de emoción al interpretar, tal como el actor inglés de la época victoriana Henry Irving, y los "anti-emocionalistas", que creían en un actor controlado y distanciado, entre los que se encontraba el actor francés Benoit Constant Coquelin. En la última década del siglo XIX Coquelin e Irving se enfrentaron en una" batalla de cartas" sobre sus respectivos acercamientos al arte del actor. Parte de esta controversia envolvió a la obra de Diderot y generó un enfrentamiento que provocó que el crítico y dramaturgo escosés William Archer, escribiera su obra ¿Máscaras o rostros? (1888) sobre la emoción en la interpretación (COLE y CHINOY 1970). Archer también se basó en la obra del actor Françoise Joseph Talma, Reflexiones sobre el arte del actor (1825), que se oponía a las ideas de Diderot e igualaba sensibilidad e inteligencia dentro del proceso artístico del actor (GORDON 2006). (Rojas, 2012, p.48-49).
}

\section{(c) (i) (2) (2)}

La Revista Estudios es editada por la Universidad de Costa Rica y se distribuye bajo una Licencia Creative Commons Atribución-NoComercial-Compartirlgual 3.0 Costa Rica. Para más información envíe un mensaje a revistaestudios.eeg@ucr.ac.cr. 
Revista Estudios, (39), 2019.

Diciembre 2019-Mayo 2020

ISSN 1659-3316

Bautista Díaz Roberto

desemboca en una reflexión sobre la metodología de la actuación ${ }^{4}$. No volveremos

a encontrar otro escrito con este enfoque crítico y compromiso con la preparación

y la formación actoral, hasta mitad del siglo XIX y principios del XX.

\section{Cambio de paradigmas}

Es precisamente en la segunda mitad del siglo XIX, durante la existencia de la compañía del Duque de Meiningen ${ }^{5}$, que se instaura una visión diferente hacia el arte interpretativo. Desde su rol de director escénico, el Duque fue privilegiando o replanteando el abordaje interpretativo en función de un intérprete integrado a la acción escénica, a la obra de arte total desde una visión Wagneriana ${ }^{6}$. Inspirado también en esta visión, André Antoine (1858-1943), fundó un modelo innovador que rompía con los estereotipos de la comedia francesa y las normas establecidas. Introduce el concepto de la "cuarta pared" con el que pretendía dotar

\footnotetext{
4 Anterior a Diderot, durante siglo XVII, encontramos dos ejemplos que haciendo uso del metateatro (teatro dentro del teatro), nos revelan una comprensión de la técnica interpretativa como un oficio amalgamado con la búsqueda discursiva y estética. En el primero de estos ejemplos el autor ofrece una serie de consejos sobre cómo llevar a cabo una interpretación sólida, cumpliendo con los objetivos de la escena y otorgándole al trabajo actoral verosimilitud, presencia y fuerza. Nos referimos a la obra The Tragicall Hiftorie of Hamlet, Prince of Denmark, escrita por William Shakespeare entre 1600 y 1601 según E. K. Chambers, (citado en D' Amico 1972, p.285). En la obra su protagonista, ofrece recomendaciones precisas a los actores que se encargan de la "representación" de la muerte de su padre. Las acotaciones a los actores que ofrece Shakespeare en la voz de Hamlet, abarcan desde la forma de decir hasta el trabajo corporal. "[...] Ajusta la acción a las palabras y las palabras a la acción, cuidado en especial de no exceder la sencillez de la naturaleza, que toda sobreactuación es ajena a la razón misma de ser del teatro, cuya finalidad, tanto en sus inicios como ahora, ha sido y es sostener, por así decirlo, un espejo ante la naturaleza que muestra a la virtud su propio rostro, al vicio su verdadera imagen y a la misma encarnación del tiempo su carácter y su sello" (Shakespeare, W. Hamlet. Acto tercero, escena segunda). El segundo ejemplo es de 1663 y aparece en el texto L'impromptu de Versailles de Moliere, "llamado así porque fue casi improvisado y puesto en escena ante el rey en el palacio de Versalles" (D’ Amico, 1972, p.329). La obra nace de la rivalidad con la compañía antagonista de la época, en el texto, su autor utiliza la sátira y la burla para revelarnos un modo de interpretación "en busca del efecto" (p.328), forma de interpretación que Moliere y sus actores consideraban falso ya que no respondían al "principio de la más llana naturalidad" (p.329).

${ }^{5}$ Duque Georg II de Meiningen (1826-1914) Revoluciona el teatro, desarrolló la idea básica de la dirección escénica, la interpretación del texto, fusionó los recursos teatrales, concientizó los planos de actuación en el escenario, la exactitud de los decorados, el cuidado por la composición, etc.

${ }^{6}$ Richard Wagner (1813-1883), transformó el pensamiento musical y escénico con la idea de la «obra de arte total» (Gesamtkunstwerk), la síntesis de todas las artes poéticas, visuales, musicales y escénicas. Propone sintetizar en un espectáculo único todas las artes.
}

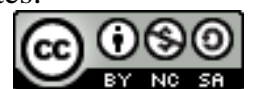

La Revista Estudios es editada por la Universidad de Costa Rica y se distribuye bajo una Licencia Creative Commons Atribución-NoComercial-Compartirlgual 3.0 Costa Rica. Para más información envíe un mensaje a revistaestudios.eeg@ucr.ac.cr. 
a las presentaciones de sus intérpretes de la mayor naturalidad posible. Si bien estos postulados todavía no generaban una praxis formativa específica, abrieron la puerta a un ejercicio actoral en coherencia con el acontecimiento estético. En otras palabras, la búsqueda estética de los creadores de la escena, como pareciera estuvo claro para Shakespeare y Moliere, demanda del creador un vínculo directo con la formación de sus intérpretes. Esto va fomentar la aparición de tendencias, corrientes, disímiles abordajes que abrirán paso a una diversidad formativa sin precedentes hasta el momento.

\section{Establecimiento de las escuelas y maestros}

La aparición de un método formativo para intérpretes de carácter holístico e integrador no va a comenzar a gestarse hasta 1888 de la mano de Konstantín Serguéievich Stanislavski. El maestro ruso fue de los primeros en ordenar pedagógicamente los principios de mayor relevancia, que según su criterio, posibilitaban adentrarse en el arte de la actuación, de la interpretación. Stanislavski, con su "sistema o método", orienta al actor hacia un camino del auto conocimiento, de comprensión de cuanto le rodea incluyendo al público. Agudiza su sensibilidad y la necesidad de una formación integral (2007, p.29). Inspirado por teorías científicas y psicológicas de la época enfocó su trabajo en la emoción del actor y en encontrar los resortes para alcanzar dicha emoción a partir de las propias experiencias de las y los intérpretes.

Luego de la muerte de Stanislavski el método comienza a ser replicado por sus continuadores. Cada uno imprime a la búsqueda su visión particular, con el afán de lograr una aprehensión propia que permitiera profundizar en la propuesta primigenia, procurando identificar de esta forma aquellos caminos que brindaran las técnicas "idóneas" a las y los intérpretes. Los caminos transitados por las y los continuadores del método ruso apelaban a lo que el propio Stanislavski 
Revista Estudios, (39), 2019.

Diciembre 2019-Mayo 2020

ISSN 1659-3316

Bautista Díaz Roberto

denominaría "naturaleza creadora". El trabajo del maestro y de sus continuadores será incluido en lo que Rojas denomina como Vertiente Stanislavskiana/Psicológica.

En paralelo a este pensamiento stanislavskiano y con motivaciones de cierta semejanza, se fue constituyendo en Francia un núcleo de estudiosos del teatro que apostaban por un actor completo y cabal. Es así como se continuó dando valor a las cualidades físicas, intelectuales y morales de los futuros intérpretes. Jacques Copeau (1879-1949), Charles Dullin (1885-1949) y Louis Jouvet (18871951), consideraban necesario fomentar un entrenamiento ${ }^{7}$ que sistematizara el trabajo actoral.

La búsqueda de nuevas pedagogías de entrenamiento y formación actoral despertó el interés de creadores como Émile Dalcroze (1865-1950), Etienne Decreaux (1898-1991), Jaques Lecoq (1921-1999), entre otros. Estos últimos, inician recorridos que se enfocaban en una preparación y acondicionamiento físico de los intérpretes en aras de una plasticidad y una conciencia gestual innovadora. Si bien estos teóricos preponderaron el trabajo corporal en su construcción escénica, no descuidaban el desarrollo simultáneo, amalgamado, del cuerpo y de la mente, es decir que de manera paralela les interesaba potenciar la expresividad y destacar el carácter humano de las y los intérpretes.

Partiendo de los antecedentes establecidos por la escuela francesa, Dalcroze por su parte, propone un método de aprensión de la rítmica y de la música en general a través de un trabajo particular con el cuerpo en el proceso formativo o preparativo actoral. "[...] basó su propuesta de entrenamiento en la gimnasia rítmica, ya que consideraba que esta técnica le facilita al actor, la toma de

7 La noción de entrenamiento se disocia entonces de la de educación, abandonada a las escuelas. Nacidas en su mayoría en el siglo XIX, de entrada son portadoras de una visión de la formación marcada por la preeminencia del texto en la escena y por la necesidad de que el actor se prepare para ocupar un "empleo" (coord. Müller, Féral, 2007, p.17).

\section{(c) (i) (9) (2)}

La Revista Estudios es editada por la Universidad de Costa Rica y se distribuye bajo una Licencia Creative Commons Atribución-NoComercial-CompartirIgual 3.0 Costa Rica. Para más información envíe un mensaje a revistaestudios.eeg@ucr.ac.cr. 
conciencia de las fuerzas de su cuerpo, lo que le permite destrabar sus gestos, tener un cuerpo dueño de sí, libre y espontaneo" (coord. Müller, Féral, 2007, p.22).

Uno de los aportes definitorios y determinantes entre estos investigadores, exponentes que Rojas agrupa en la Vertiente Gestual, fue el trabajo que introdujera Jacques Copeau con las máscaras. La propuesta de Copeau se alimentaba del trabajo con las máscaras recurrentes en el teatro tradicional japonés Noh. Dicha concepción fue desarrollada por unos de sus discípulos Jean Dasté (1904-1994), quien crea una máscara inexpresiva que adquirió el nombre de "máscara noble". Dicha herramienta pedagógica obligaba a las y los intérpretes en formación, a canalizar todo el potencial comunicativo a través de todo su cuerpo y no solo en el rostro. "Mediante la máscara noble o neutra se difuminan los rasgos faciales del actor y se le sitúa en un punto de neutralidad que, al tiempo que lo aleja de su comportamiento cotidiano, lo acerca a una presencia escénica eficaz" (Ruiz, 2012, p.225).

Otro heredero de la mencionada escuela es Jacques Lecoq. Lecoq propone un entrenamiento donde el trabajo con el cuerpo se vuelve el centro de la investigación. A dicha propuesta se suma la experiencia con la Máscara Neutra creada por Copeau, que Lecoq desarrolla a profundidad introduciendo lo que denominó Máscara Larvaria. Esto se nutre con el trabajo corporal y la aplicación de las técnicas de la Comedia dell' Arte con las que se familiarizara el maestro francés en una experiencia previa en tierras italianas. Su propuesta formativa también vincula la técnica del Mimo Corporal de Decroux, la Euritmia de Dalcroze. Todo en pos de la búsqueda de un "Cuerpo Poético".

\section{(c) (i) (2)}

La Revista Estudios es editada por la Universidad de Costa Rica y se distribuye bajo una Licencia Creative Commons Atribución-NoComercial-CompartirIgual 3.0 Costa Rica. Para más información envíe un mensaje a 
Revista Estudios, (39), 2019.

Diciembre 2019-Mayo 2020

ISSN 1659-3316

Bautista Díaz Roberto

Especificidades de la formación actoral dentro de la Vertiente Piscofísica/ Intercultural. Algunos exponentes

En este apartado pretendemos evidenciar el compromiso y rigor que adquiere la preparación del actor en esta tendencia formativa. Rescatando el trabajo de algunos exponentes podremos constatar cómo el "cuerpo" va a ser medular en la formación actoral dentro de estas pesquisas. Lo anterior con la intención de identificar lo que consideramos requerimientos expresivos resultantes de un trabajo formativo marcado por el entrenamiento psicofísico.

La propuesta Psicofísica/Intercultural aboga por una integralidad manifiesta que persigue la comunión del cuerpo y la mente del actor. Si bien esta comunión ha sido objetivo en el trabajo de otras vertientes, lo distintivo de esta, es que el cuerpo se va a volver vehículo para dicho fin, haciéndolo atravesar por prácticas psicofísicas enriquecidas por las experiencias absorbidas de culturas, en ocasiones, diferentes a las y los investigadores en cuestión. Es por ello que revierte un interés puntual para nosotros, ya que consideramos que asumir el proceso formativo actoral desde la sensorialidad del cuerpo como un todo, integrando a su vez el saber de la práctica escénica universal, nos permite generar experiencias que se instauran en los diferentes planos perceptivos de las y los intérpretes.

Consideramos que la mente entiende cuando el cuerpo aprehende; despertar el cuerpo pensante de los y las intérpretes, presupone una sintonía con lenguajes particulares que han de desembocar en poéticas específicas. Dichas poéticas comienzan a alimentarse de manera consiente de diferentes fuentes como las prácticas del teatro oriental, el teatro japonés, las artes marciales, el yoga, entre otros insumos que son conjugados por la vía de la gimnasia, la psicología, la antropología, entre otras. Una profundidad en el entrenamiento de enfoque

La Revista Estudios es editada por la Universidad de Costa Rica y se distribuye bajo una Licencia Creative Commons Atribución-NoComercial-Compartirlgual 3.0 Costa Rica. Para más información envíe un mensaje a 
psicofísico para el actor, será sin duda alguna, el elemento coincidente entre las diferentes propuestas que acoge esta vertiente. Sin traicionar su visión individual, cada exponente consagra gran parte del proceso formativo a la preparación tanto física como psicológica, introduciendo al intérprete en un camino de autoconocimiento y autodominio de sus posibilidades físicas e interpretativas.

Un ejemplo de esto se puede ver durante en la primera mitad del siglo XX. Para la década de 1920 Vsévolod Meyerhold (1874-1947), ex alumno de Stanislavski, propone desde su teoría y práctica teatral un nuevo concepto de entrenamiento actoral. "La biomecánica en su origen, fue un entrenamiento constituido por una serie de ejercicios y de études. Los études son rutinas psicofísicas con un diseño muy preciso que comprendía de forma práctica los principios de la biomecánica" (Ruiz, 2012, p.127). Esta nueva idea no solo se establece en el entrenamiento de los actores, sino que desembocaba también en una estética del cuerpo y de la concepción escénica, que termina permeando espectáculos que mostraban a intérpretes de una expresión potenciada, pertinente y emblemática del expresionismo de la escena rusa de su época. Para Meyerhold el entrenamiento debe ser integral e integrador, el cuerpo entero del actor participa en cada uno de sus movimientos. "Si la punta de la nariz trabaja, todo el cuerpo también trabaja". 8

Existía entonces, por parte de los representantes de esta vertiente, una preocupación por asumir el cuerpo como un todo expresivo, a la vez que maximizaban el compromiso de todos los segmentos posibles en una acción, que en un contexto cotidiano, solo comprendía una parte específica del cuerpo o determinado miembro. Todas las acciones que se ejecutaban en escena, más allá de la capacidad semiótica intrínseca de la misma, adquirían una dimensión y presencia porque eran pensadas desde la integración, a partir de la manipulación de la energía y el impulso. "El tiro con arco", ejercicio que incluye el maestro en la biomecánica, podría ser muy útil para mostrar esta idea de un cuerpo total en

8 Mijail Korenev, colaborador de Meyerhold, citado en Ruiz, 2012, p.124.

La Revista Estudios es editada por la Universidad de Costa Rica y se distribuye bajo una Licencia Creative Commons Atribución-NoComercial-CompartirIgual 3.0 Costa Rica. Para más información envíe un mensaje a revistaestudios.eeg@ucr.ac.cr. 
Revista Estudios, (39), 2019.

Diciembre 2019-Mayo 2020

ISSN 1659-3316

Bautista Díaz Roberto

acción. En dicho ejercicio se van articulando o integrando a la acción, todos los segmentos en una suerte de danza que se origina desde los pies.

Técnicamente, esto se produce gracias a una traslación del impulso: en la biomecánica son las piernas las que generan el impulso en todas las acciones. [...] por lo tanto, el impulso que originalmente nace en el brazo, se traslada a las piernas y de ahí se transmite a todo el cuerpo. (Ruiz, 2012, p.124).

Con igual profundidad de estudio Jerzy Grotowsky (1933-1999) fue estableciendo su concepción estética, la cual se fundamentaba en un viaje hacia las fuentes donde el ritual adquiere una dimensión determinante en su trabajo; "[...] cuando el ritual "está hecho a la faz de lo divino" es ritual; cuando en cambio "está hecho a la faz de los espectadores" es teatro" ${ }^{\prime}$. Grotowsky aboga por un teatro que coloca al actor en el centro de su búsqueda y creación. Dicha concepción concebía la necesidad de un "actor "Santo"10". Desde esta visión planteó un entrenamiento donde cada ejercicio sería abordado desde lo psicofísico. El actor debía asumir cada ejercicio físico estableciendo conexiones análogas ${ }^{11}$ que permitieran trabajar el cuerpo y la mente, agudizando la conciencia corporal, el estado de alerta, la presencia escénica, etc. Esta relación con el entrenamiento permitía que cada intérprete emprendiera una búsqueda individual para borrar las resistencias. Y es que en su concepción el "[...] aspecto medular del arte teatral es la técnica escénica y personal del actor" (Grotowski, 1992, p.9).

9 Grotowski citado en Sais 2015, p.28.

$10 \mathrm{El}$ teatro tiene- que reconocer sus propias limitaciones. No puede ser más rico que el cine, dejemos que sea pobre. Si no puede ser tan atractivo como la televisión, dejemos que sea ascético. Si no puede ser una atracción técnica, renunciaremos a toda la técnica exterior. De esta manera nos que damos con un actor "santo" en un teatro pobre (Grotowsky, 1992, p.36).

11 Hasta durante los ejercicios de calentamiento el actor debe justificar cada detalle de su entrenamiento con una imagen precisa, ya sea real o imaginaria. El ejercicio se ejecuta correctamente sólo si el cuerpo no opone ninguna resistencia durante la realización de la imagen en cuestión (Grotowski, 1992, p.96).

\section{(c) (i) (2)}

La Revista Estudios es editada por la Universidad de Costa Rica y se distribuye bajo una Licencia Creative Commons Atribución-NoComercial-CompartirIgual 3.0 Costa Rica. Para más información envíe un mensaje a revistaestudios.eeg@ucr.ac.cr. 
Nada se hace en frío, incluso los pocos ejercicios de relajación preliminares deben ser ejecutados pensando, por ejemplo, que se tiene un cuerpo maleable, o rígido, o alguna otra idea que justifique los movimientos. El entrenamiento corporal debe estar exento de todo contenido puramente gímnico o coreográfico. Los movimientos son ejecutados en relación con otros, con algún objeto, como reacción contra el mundo exterior; están motivados, en lugar de ser hechos en vacío. (Aslan, 1979, p.257).

Toda impronta física debía responder a detonantes que se gestaban en la mente, en la imaginación del actor. Según el maestro, se hacía necesario asumir la formación actoral desde un teatro laboratorio ${ }^{12}$, abandonando toda forma preconcebida. "La nuestra es una vía negativa, no una colección de técnicas, sino la destrucción de obstáculos" (Grotowski, 1992, p.11). Dentro de su exploración escénica el entrenamiento llegó a ser tremendamente riguroso lo que exigía una especie de consagración.

Los derroteros por los que transitaron investigadores como Jerzy Grotowski, Eugenio Barba(1936-), Tadashi Suzuki(1939-), Phillip Zarrilli(1947-), entre otros, les llevaron a plantear sus búsquedas desde la formulación de un tipo de teatro laboratorio, presente ya en la intención renovadora de Copeau con el teatroescuela Vieux Colombier.

Eugenio Barba, discípulo de Grotowski, se apropia de toda la experiencia del laboratorio Grotowskiano y conduce sus pesquisas a través de la antropología teatral ${ }^{13}$. Para Barba era necesario revisitar algunas prácticas teatrales milenarias,

12Teatro experimental donde los actores efectúan investigaciones sobre la actuación o la puesta en escena, sin preocuparse por la rentabilidad comercial e incluso sin considerar como indispensable la presentación del trabajo terminado a un gran público (ej.: el Laboratorio Arte y Acción, de E. AUTANT y L. LARA, el Teatro Laboratorio de Grotowski) (Pavis, 1980, p.488).

13 La antropología teatral es el estudio del comportamiento biológico y cultural del hombre en una situación de representación, es decir del hombre que utiliza su presencia física y mental según principios distintos a los

La Revista Estudios es editada por la Universidad de Costa Rica y se distribuye bajo una Licencia Creative Commons Atribución-NoComercial-CompartirIgual 3.0 Costa Rica. Para más información envíe un mensaje a revistaestudios.eeg@ucr.ac.cr. 
Revista Estudios, (39), 2019.

Diciembre 2019-Mayo 2020

ISSN 1659-3316

Bautista Díaz Roberto

pues en ellas aún radicaba la esencia de un teatro más cercano a la forma y estética que perseguía. Es por ello que compila en sus estudios prácticas teatrales y danzarías de la India e Indonesia, así como el desempeño y la conciencia física de los intérpretes de manifestaciones teatrales de Asia como el Kabuki, el Noh, la Ópera de Pekín, entre otras. Partiendo del análisis de los procesos formativos en las variantes teatrales antes mencionadas, podemos identificar que Barba desarrolla un entrenamiento que le permite estructurar conceptos como la Danza de las Oposiciones ${ }^{14}$, el trabajo con los Sats $^{15}$ y la búsqueda de la preexpresividad $^{16}$, de una presencia escénica extra-cotidiana. Al situar su búsqueda desde la antropología, son muchas las técnicas y los estilos de trabajo corporal que permean su creación.

Tadashi Suzuki quien recoge gran parte de propuesta en el texto La cultura es el cuerpo (2015), apunta su investigación a la herencia del teatro japonés Noh. Esta manifestación escénica se vuelve referente para replantear, desde su estética, el proceso formativo de los actores y actrices de su compañía. Distintivo se vuelve entonces el trabajo que sus discípulos comienzan a realizar con los pies, con el objetivo de rescatar en su teatro la vitalidad física y presencial propia de los actores del teatro tradicional japonés.

La génesis de esta forma de concienciación y entrenamiento puede ser encontrada en rituales ancestrales de la propia cultura, los sonidos que se producen golpeando el suelo con los pies y el ritmo que van adquiriendo los

\footnotetext{
de la vida cotidiana. Esta utilización particular, extra cotidiana, del cuerpo en el teatro, es lo que se llama técnica. (Barba, 1988, p.7).

14 El actor chino, antes de realizar una acción, empieza siempre por su lado contrario. Por ejemplo: para mirar a una persona que está sentada a su derecha, el actor occidental, más o menos haría lo siguiente: un movimiento directo, lineal de la nuca. Pero el actor chino y la mayoría de actores orientales empezarían el movimiento como si quisieran mirar al otro lado y cambiando repentinamente la dirección, posarían la mirada sobre la persona en cuestión. (Barba, 1988, p.43)

15 Palabra noruega, el sats describe una posición de alerta en el actor, una postura a partir de la cual se puede realizar cualquier acción hacia cualquier dirección. (Ruiz, 2012, p.421) Instante que precede a la acción. 16 La pre-expresividad del actor, el estar en condiciones de cobrar vida en el escenario utilizando los principios de oposición propuestos por el propio autor.
}

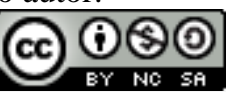

La Revista Estudios es editada por la Universidad de Costa Rica y se distribuye bajo una Licencia Creative Commons Atribución-NoComercial-CompartirIgual 3.0 Costa Rica. Para más información envíe un mensaje a revistaestudios.eeg@ucr.ac.cr. 
Revista Estudios, (39), 2019.

Diciembre 2019-Mayo 2020

ISSN 1659-3316

Bautista Díaz Roberto

mismos, producen una energía que conduce a los ejecutantes "a una presencia física y espiritual fuera de los límites cotidianos de la existencia" (Ruiz, 2012, p. 494-495).

La forma en la que se utilizan los pies en escena determina la actuación. Lo que hacen los movimientos de los brazos y de las manos es apoyar el sentimiento inherente que surge en la postura del cuerpo, predeterminada a su vez por los pies. A menudo la posición de los pies determina incluso la fuerza y los matices de la voz en el actor. Un actor puede prescindir de sus brazos o manos, pero es inconcebible que actúe sin pies. (Suzuki citado en Ruiz, 2012, p.495).

Además de la parte preponderante que ocupa en el entrenamiento de Suzuki el trabajo con los pies, existe otro segmento del cuerpo al que el investigador otorga gran protagonismo, nos referimos al hara ${ }^{17}$. Dentro de la propuesta se establece esta parte del cuerpo del actor como su centro físico y emocional. Tomando en cuenta lo anterior, podríamos decir que el destino de la propuesta se encamina a una concienciación y despertar del centro de gravedad del intérprete, a través de rigurosos ejercicios que resultan en una exacerbación de la resistencia, la presencia y la potencia física.

Otro de los que apoya su búsqueda en referentes más allá del universo Occidental es Phillip Zarrilli. El maestro a diferencia de otros, se vuelve su propio objeto de estudio, partiendo de su vasta experiencia en artes marciales de la India (Kalaripayattu) y el Hata Yoga, conjuga sus conocimientos en un abordaje intercultural de su propuesta.

\footnotetext{
17 Hara: Palabra japonesa que designa el centro energético situado entre la pelvis, a unos tres centímetros por debajo del ombligo. En la cultura japonesa el hara constituye el núcleo de todo ser, allí donde residen la fuerza, la salud, la energía, la integridad de una persona y la percepción que tiene de su relación con el mundo y el universo. En las artes escénicas tradicionales de Japón... la presencia escénica de los actores se basa en la capacidad de absorber e irradiar la energía desde dicho centro.
}

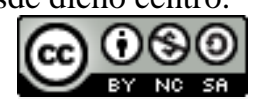

La Revista Estudios es editada por la Universidad de Costa Rica y se distribuye bajo una Licencia Creative Commons Atribución-NoComercial-CompartirIgual 3.0 Costa Rica. Para más información envíe un mensaje a revistaestudios.eeg@ucr.ac.cr. 
Simultáneamente, a través de un largo proceso de repetición de formas básicas de práctica, gradualmente comencé a sentir un cambio en la calidad de mi relación con mi cuerpo-mente en el ejercicio o en el escenario. Estaba descubriendo una energía interna que podía controlar y modular, física y vocalmente, ya sea en el desempeño o cuando extiendo mi respiración o energía a través de un arma al lanzar un golpe. Me estaba moviendo de una preocupación por la forma física y externa, a la conciencia de la dimensión interna (psico) más sutil de cómo encarnar completamente una acción. (Zarrilli, 2009, p.24). (traducción propia)

Siendo consciente de las expectativas interpretativas de la escena contemporánea encamina su búsqueda de un actor cuyo trabajo no quede restringido a roles enmarcados en un lenguaje realista. Para Zarrilli las actrices y los actores contemporáneos deben ser capaces de transitar por un amplio espectro de técnicas y poéticas interpretativas que les permitan peregrinar por diferentes alternativas escénicas. Para ello apela a la mencionada comunión del cuerpo y la mente a partir del entrenamiento psicofísico y al desarrollo del universo interior de las y los intérpretes.

\section{Valoraciones finales}

Luego de este bosquejo podemos concluir que a pesar de las diferencias de los caminos asumidos por cada creador, existe una comunión en sus objetivos formativos. La visión que rige las pesquisas de los representantes de la vertiente psicofísica/intercultural posibilita asumir la formación actoral con mayor conciencia de una universalidad del fenómeno interpretativo, que no desdeña sino que persigue imbricar experiencias globales que aporten solidez y profundidad al arte interpretativo.

\section{(c) (i) (9) (2)}

La Revista Estudios es editada por la Universidad de Costa Rica y se distribuye bajo una Licencia Creative Commons Atribución-NoComercial-CompartirIgual 3.0 Costa Rica. Para más información envíe un mensaje a 
Revista Estudios, (39), 2019.

Diciembre 2019-Mayo 2020

ISSN 1659-3316

Bautista Díaz Roberto

Como hemos procurado mostrar, la preparación actoral desde hace muchas décadas, apuesta por una formación integradora que atraviese niveles físicos e involucre el ámbito psicológico, muscular, espiritual, moral, racional, de quienes se adentran en el universo de la interpretación.

Se vuelve evidente el inmenso porcentaje de propiocepción requerido dentro del proceso formativo actoral. "Además del tradicional entrenamiento en esgrima y artes marciales, el actor debería aprender a pensar en defensa propia" (Tavira, s.f, p.93). Es por ello que definir un entrenamiento para actores y actrices, debe suponer formular un sistema que logre, de alguna manera, concienciar y potenciar todas las esferas que componen al ser humano, quien es en definitiva el único ser vivo capaz de interpretar.

El abordaje formativo en la vertiente psicofísica/intercultural, involucra el cuerpo desde una visión empírica que logra instaurar experiencias que trascienden lo racional. En el cuerpo de las y los intérpretes incide el contexto y a través de este, se articula, se manifiesta en el espacio. "Existimos ya que poseemos un cuerpo que llena los espacios de la realidad y lo ficticio" (Blasco, 2007, p. 86). La búsqueda de un "cuerpo" cargado de organicidad y verosimilitud interpretativa, ha sido un objetivo recurrente en todos los abordajes formativos a lo largo de la historia. Sin embargo, desde los postulados que se manifiestan en esta vertiente, comprendemos que el camino de la formación actoral no debe estar restringido a una geografía epistémica, sino que debe estar abierto a cualquier experiencia o práctica que posibilite el autoconocimiento y la potenciación de las cualidades expresivas.

El cuerpo de los y las intérpretes es el signo icónico a mitad de camino entre el objeto y su simbolización (Pavis, 1980), es la herramienta y el espacio donde ocurre la poiesis. Encontrar el camino formativo idóneo, va a estar condicionado por los lenguajes y estéticas que se persiguen. Sin embargo, la exigencia y compromiso adquirido dentro de las propuestas de los exponentes de la vertiente

\section{(c) (i) (2)}

La Revista Estudios es editada por la Universidad de Costa Rica y se distribuye bajo una Licencia Creative Commons Atribución-NoComercial-CompartirIgual 3.0 Costa Rica. Para más información envíe un mensaje a revistaestudios.eeg@ucr.ac.cr. 
psicofísica/intercultural pareciera ser, hasta el momento, uno de los caminos que logra imbricar los principios de las otras vertientes mientras que dota a las y los actores en formación, de un arsenal teórico y técnico que les permitirá asumir la interpretación desde cualquier, género, estética, estilo o lugar de enunciación.

\section{Bibliografía}

Asían, O. (1979). El actor en el siglo XX. Evolución de la técnica, problema ético. Barcelona: Editorial Gustavo Gili, S. A.

Barba, E. \& Savarese, N. (1988). Anatomía del actor, Diccionario de antropología teatral. México: Grupo Editorial Gaceta S.A de C.V.

Barba, E. \& Savarese, N. (2007). El arte secreto del actor. Diccionario de antropología teatral. (2da ed.). La Habana, Cuba: Ediciones Alarcos.

Blasco, J. A. (enero-junio, 2007). Un cuerpo inhala o la presencia de la expresión. Artes, La revista, 7(13), 86-89.Recuperadode:

https://aprendeenlinea.udea.edu.co/revistas/index.php/artesudea/article/vie w/23762/19496.

Carvajal, M. 2015. El entrenamiento del actor en el siglo XX. Fundamenmtos etimológicos, ontológicos, científicos y pedagógicos (Tesis de doctorado). Universidad Autónoma de Barcelona.

Ceballos, E. (2013). Principios de la Dirección Escénica. México. Escenología.

D' Amico, S. (1972). Historia del teatro dramático. La Habana, Cuba: Instituto Cubano del Libro.

Dennis, A. (2014). El cuerpo elocuente. La formación física del actor. Madrid, España: Editorial Fundamentos.

Grotowski, J. (1992). Hacia un teatro pobre. México D.F: Siglo XXI editores.

Lecoq, J. (2011). El cuerpo poético. Barcelona, España: Alba Editorial. S.I.u, quinta edición.

\section{(c) (i) (2)}

La Revista Estudios es editada por la Universidad de Costa Rica y se distribuye bajo una Licencia Creative Commons Atribución-NoComercial-CompartirIgual 3.0 Costa Rica. Para más información envíe un mensaje a 
Meyer-Dinkgräfe, D. (2001). Approaches to Acting Past and Present. New York: ed. Vol. Continuum.

Müller, C. (Ed.). (2007). El training del actor. ed. Vol. México D.F: unam-imba.

Pavis, P. (1980). Diccionario del teatro. Dramaturgia, estética, semiología. Barcelona, España. Ediciones Paidós.

Pavis, P. (2016). Diccionario de la performance y del teatro contemporáneo. Ciudad de México. Paso de Gato.

Quintiliano, M.F. (s.f) Instituciones Oratorias. Biblioteca Virtual Universal. Recuperado de:https://biblioteca.org.ar/libros/154922.pdf

Rojas, E. (2012). Metodología de la enseñanza de la interpretación teatral. Algunos ejemplos (Tesis de doctorado). Universidad del Rey Juan Carlos de Madrid.

Ruiz, B. (2012). El arte del actor en el siglo XX. Un recorrido teórico y práctico por las vanguardias (2da ed.). Bilbao: Artezblai SL.

Sais, P (2015). Hacia una poética del arte como vehículo de Jerzy Grotowski.

(Tesis de doctorado).Universiad Autónoma de Barcelona.

Schinca, M. (2002). Expresión Corporal Técnica y Expresión el Movimiento. (3er ed. Vol.) Barcelona: PRAXIS.

Stanislavski, K. (2007). El trabajo del actor sobre sí mismo en el proceso creador de la vivencia. España: Alba Editorial. Traduc Jorge Saura.

Stanislavski, K. (2009). El trabajo del actor sobre sí mismo en el proceso creador de la encarnación. España: Alba Editorial. Traduc Jorge Saura.

Tadashi, S. (2015). Culture is the body. New York, NY. Theatre Communications Group.

Tavira, L. (s.f). El espectáculo invisible. Paradojas sobre el arte de la actuación. Mardid, España.Serie "Debate" n`9.

Zarrilli, P. (2009). Psychophysical acting. An intercultural approach after Stanislavski. New York, NY: Routledge.

\section{(c) $($ ) (2) (2)}

La Revista Estudios es editada por la Universidad de Costa Rica y se distribuye bajo una Licencia Creative Commons Atribución-NoComercial-CompartirIgual 3.0 Costa Rica. Para más información envíe un mensaje a 